\title{
O mestrado nacional profissional em ensino de física no Brasil: caracterizando a proposta
}

\author{
The national professional masters in physics teaching in Brazil: \\ characterizing the proposal
}

Elisangela Rovaris Nesi

Doutoranda

Programa de Pós-Graduação em Educação para a Ciência e Matemática - UEM.

Campo Mourão, Paraná- Brasil.

elisangelanesi@gmail.com

\begin{abstract}
Michel Corci Batista
Doutor em Educação para a Ciência e Matemática Universidade Tecnológica Federal do Paraná- UTFPR.

Campo Mourão, Paraná - Brasil. michel@utfpr.edu.br

Natália Neves Macedo Deimling Doutora em Educação Universidade Tecnológica Federal do Paraná- UTFPR. Campo Mourão, Paraná - Brasil. natalian@utfpr.edu.br
\end{abstract}

Resumo: Este artigo tem como objetivo tecer algumas considerações a respeito das características do Mestrado Nacional Profissional em Ensino de Física (MNPEF) enquanto mestrado profissional de uma área específica inserido em uma política nacional de formação docente. $\mathrm{O}$ artigo traz uma discussão a respeito da importância dos mestrados com ênfase no MNPEF, identificando os elementos que o definem no âmbito de uma proposta formativa em exercício. Trata-se de um estudo qualitativo que utiliza a análise documental descritiva para interpretação dos dados e constituição dos resultados. Entre outros aspectos, este trabalho evidencia o MNPEF como uma proposta nova que já dispõe de alguns passos e que vem demonstrando possibilidades e desafios.

Palavras chave: ensino de física; formação continuada; formação de professores; mestrado profissional.

Abstract: This article aims to make some considerations about the characteristics of the National Professional Master's Degree in Physics Teaching (MNPEF, acronym in Portuguese) as a professional master's degree in a specific area inserted in a national policy for teacher training. The article presents a discussion about the importance of master's degrees with an emphasis on the MNPEF, identifying the elements that define it within the scope of an in-service training proposal. This is a qualitative study that uses descriptive document analysis for data interpretation and results constitution. Among other aspects, this work highlights the MNPEF as a new proposal that already has some steps and that has been demonstrating possibilities and challenges.

Key-words: physics teaching; continuing education; teacher training; professional master's degree.

Cite como

(ABNT NBR 6023:2018)

NESI, Elisangela Rovaris; BATISTA, Michel Corci; DEIMLING, Natália Neves Macedo. O mestrado nacional profissional em ensino de física no Brasil: caracterizando a proposta. Dialogia, São Paulo, n. 38, p. 1-21, e20420, maio/ago. 2021. Disponível em: https://doi.org/10.5585/38.2021.20420.

American Psychological Association (APA)

Nesi, E. R., Batista, M. C., \& Deimling, N. N. M. (2021, maio/ago.). O mestrado nacional profissional em ensino de física no Brasil: caracterizando a proposta. Dialogia, São Paulo, 38, p. 1-21, e20420. https://doi.org/10.5585/38.2021.20420. 


\section{Introdução}

Ao longo das últimas décadas, a formação de professores tem sido discutida por pesquisadores com diferentes focos de interesses (PIMENTA; GHEDIN, 2005; FREITAS, 2002; FACCI, 2004; BRZEZINSKI, 2008; ANDRÉ, 2010; SHIROMA; MORAES; EVANGELISTA, 2011; ROMANOWSKI, 2012). Esses estudos trazem um campo vasto de discussão em que são abordados criticamente os aspectos educacionais que permeiam as produções teóricas sobre formação docente, as concepções dos professores, os problemas que envolvem o espaço escolar, bem como as condições objetivas e subjetivas de trabalho e carreira docente. Nestes estudos também são elencados programas de formação docente ofertados ao longo de décadas por políticas com propostas educacionais que regulamentam e controlam o ensino público no país, caracterizando a importância da formação continuada como processo que pode oportunizar aos educadores a retomada de conceitos, discussões e reflexões de sua formação inicial a partir da análise de suas condições de trabalho e da prática pedagógica.

Considerando a amplitude das pesquisas realizadas por diferentes autores, cada qual com focos específicos e, ao mesmo tempo, complementares, discutimos neste trabalho a formação continuada de professores de Física oportunizada em um mestrado específico: o Mestrado Nacional Profissional em Ensino de Física (MNPEF). Trata-se de um programa em nível de Mestrado desenvolvido na modalidade profissional e idealizado pela Sociedade Brasileira de Física (SBF) em parceria com algumas universidades brasileiras, sendo voltado a profissionais em exercício que lecionam a componente curricular Física na educação básica. Entre outros aspectos, este programa entende a formação continuada como espaço acadêmico de enriquecimento profissional.

Assim, considerando a relevância que a formação continuada tem para o processo de desenvolvimento profissional docente, buscamos com este artigo tecer algumas considerações a respeito das características do MNPEF, tendo em vista compreender como esta formação vem sendo desenvolvida no Brasil ao longo das últimas décadas e como este programa, que vem expandindo-se em todo o território brasileiro, pode contribuir para a melhoria do trabalho educativo dos profissionais que dele participam.

Trata-se de um ensaio teórico de abordagem qualitativa e de caráter bibliográfico (GIL, 2002; BARROS; LEHFELD, 2007), tendo como fontes os documentos e instrumentos legais que fundamentam o MNPEF, bem como artigos científicos e dissertações que têm este programa como objeto de estudo, publicados a partir do ano de 2013. Estes trabalhos discutem e problematizam a formação continuada de professores realizada nesse modelo e nos permitem analisar pontos de 
aproximação e controvérsias a respeito do programa, assim como suas contribuições e desafios para a formação de professores de Física. Considerando ser este um mestrado desenvolvido em âmbito nacional, as produções já existentes sobre ele permitem sua exploração, revisão e análise numa perspectiva mais ampla, podendo gerar novas interpretações e proposições que podem contribuir para o avanço dos estudos sobre o tema.

\section{A formação continuada de professores no Brasil}

Compreender a docência implica entender o professor como um profissional da educação que, como tal, deve ser formado em cursos superiores de qualificação profissional, com longo tempo de exposição teórica e prática ao ato de ensinar e de aprender e com capacidade investigativa sobre a prática social. Partindo deste princípio, Facci (2004) defende que, enquanto profissional, o professor deve gozar de prestígio social e condições de trabalho e de carreira condizentes com a complexidade do trabalho que desenvolve. Entre as condições de trabalho e de carreira está a formação continuada que, aliada à formação inicial e à experiência profissional, deve contribuir para o desenvolvimento de uma prática pedagógica cada vez mais coerente e intencional, atendendo às necessidades que a própria profissão, o contexto de trabalho e a sociedade como um todo podem demandar.

Para Brzezinski (2008), as políticas de formação inicial e continuada de professores tendem a fazer parte de diferentes projetos de sustentação. Um deles é representado por tecnocratas que primam pela manutenção do sistema reprodutivo do capital numa perspectiva metodológica em que o professor é entendido como um mero executor de práticas previamente definidas. Este modelo contribui para o processo de mercantilização da educação.

A formação continuada de professores, principalmente a partir de 1990, tem se constituído como espaço propício para a disseminação das políticas neoliberais que, a partir de interesses internacionais, visam promover a globalização, característica eminente do capitalismo que de tempos em tempos utiliza-se das políticas educacionais para inserir novas propostas que atendam ao mercado de trabalho. Como afirmam Shiroma, Moraes e Evangelista (2011), nessa concepção o professor é entendido como o agente de mudança, cabendo a ele desenvolver todas as competências pedagógicas e receber os treinamentos necessários para reforçar as ideias, a cultura e os valores morais a serem desenvolvidos junto aos educandos.

Nesse modelo formativo, o foco se estabelece no professor que, com seus conhecimentos tácitos construídos a partir das experiências pedagógicas e reflexões da prática, passa a assumir as responsabilidades sobre a qualidade na educação. Trata-se, portanto, de uma concepção de 
formação pautada no praticismo e no individualismo, a partir da qual o professor passa a realizar um trabalho isolado e os problemas educacionais se deslocam da sociedade para o profissional, exigindo-lhe reflexão e qualificação permanente para modernizar a educação e atender à sociedade tecnológica numa perspectiva pragmática (SANTOS; BATISTA NETO, 2016).

Visando superar essa visão empresarial para a educação na formação docente temos associações e fóruns nacionais que defendem a qualificação e a valorização dos professores, de sua formação e carreira para o alcance dos objetivos educacionais para além das demandas de mercado, tais como a Associação Nacional de Pós-Graduação e Pesquisa em Educação (ANPED), a Associação Nacional de Docentes do Ensino Superior (ANDES), a Confederação Nacional dos Trabalhadores em Educação (CNTE), entre outras entidades engajadas na luta em prol de uma educação que valorize o trabalho desenvolvido pelo professor alicerçado em condições objetivas e subjetivas adequadas (FREITAS, 2002).

Em que pese a diversidade de linhas de ação, foram desenvolvidos no país ao longo das últimas décadas programas voltados à formação inicial e continuada de professores que visam, ao mesmo tempo, suprir a necessidade de formação de professores para a educação básica e delinear uma política que adéque a formação e a atuação do professor ao novo modelo de sociedade que se busca estabelecer, em consonância com as exigências internacionais. Para entender o atual contexto das políticas públicas de formação inicial e continuada de professores, tem-se como referência os direcionamentos apontados a partir de 2014 com a aprovação do Plano Nacional de Educação, decênio 2014/2024 (BRASIL, 2014), e as novas Diretrizes Curriculares Nacionais para a formação docente que, com a Resolução no 02/2019 (BRASIL, 2019), definiu a Base Nacional Comum para a formação inicial e continuada de professores (BNC - Formação).

Algumas entidades como a Associação Nacional pela Formação dos Profissionais da Educação (ANFOPE), a ANPED, o Fórum Nacional de Diretores de Faculdades, Centros de Educação ou Equivalentes das Universidades Públicas (FORUMDIR) e alguns fóruns estaduais e entidades acadêmico-científicas apresentaram um posicionamento contrário ao Parecer e à Minuta da Resolução do Conselho Nacional de Educação (CNE) sobre as novas diretrizes para a formação de professores. No documento são registrados os aspectos dessas diretrizes que buscam romper com a unidade da educação básica, reduzindo o processo formativo docente ao currículo escolar numa perspectiva meramente instrumental. Todavia, além de desconsiderar o princípio federativo republicano e legal de autonomia pedagógica dos sistemas estaduais e municipais na construção de seus Projetos Político-Pedagógico (em todos os níveis e modalidades de ensino), o CNE também ignorou tais apontamentos e críticas feitas pelas entidades e fóruns nacionais e estaduais a respeito 
das limitações deste novo documento que deve nortear a reestruturação dos cursos de formação de professores no Brasil.

Freitas (2007) afirma que em diferentes governos as ações focadas na formação docente têm mantido o mesmo modus operandi, construído na lógica neoliberal e mantendo reformas pragmáticas de caráter tecnicista e individualista. Duarte Neto (2013) registra ainda a ênfase que se dá ao aspecto econômico na formação docente em relação a outros fatores e indica a necessidade de se considerar todo o contexto formativo, tendo em vista projetos que libertem os sujeitos da imediaticidade na tomada de ações, sem reflexão e análise teórica que, por sua vez, pode conduzir os profissionais da educação ao esvaziamento de sua formação e a desvalorização do seu trabalho docente.

Os desdobramentos da política educacional brasileira numa perspectiva neoliberal têm como base as sugestões e condicionalidades apresentadas pelo Banco Mundial, Banco Interamericano de Desenvolvimento (BID) e pela organização dos Estados Americanos, que, entre outros aspectos, projetaram na educação a possibilidade de crescimento econômico a partir da formação de trabalhadores adaptáveis, com capacidade de adquirir novos conhecimentos em curto espaço de tempo, atendendo aos anseios da economia (SHIROMA; MORAES; EVANGELISTA, 2011).

A política educacional brasileira e os estudos sobre ela desenvolvidos evidenciam a busca para atingir esses propósitos e interesses dos organismos multilaterais para atender às expectativas do mercado neoliberal. Em meio a estes propósitos está o professor e as políticas norteadoras de formação que colocam nele a responsabilidade sobre o sucesso ou o fracasso escolar, atendendo aos interesses neoliberais em educação.

Para Freitas (2003), diante de tais exigências emergem os programas de formação continuada como propostas educativas para atender à hegemonia dominante, seja pela via estatal, seja pela iniciativa privada. Tratam-se de diferentes propostas que têm sido implementadas no âmbito do Ministério da Educação para atender a essa demanda, sendo a universidade uma das instituições fomentadoras de programas e cursos dessa natureza.

São diversas as concepções para a formação continuada de professores, com focos direcionados para a ação do professor, para o educando ou ainda para as técnicas das práticas educativas pensando nos interesses da classe dominante. Existem, ainda, propostas de formação que apresentam uma visão mais ampla de educação, permitindo ao educador redefinir suas ações pedagógicas e intervir criticamente no meio em que atua, tendo como propósito atender aos 
interesses da classe trabalhadora e romper com os limites estabelecidos pela ordem capitalista (NESI, 2015).

Ao romper com a proposta neoliberal de formação de professores, a organicidade dos movimentos educacionais prima por uma concepção formativa crítica e emancipadora. Para efetivar essa concepção de formação com mudanças que conduzam à qualidade na educação é preciso investimentos massivos na área, o que inclui melhores condições de trabalho docente, tais como: valorização da carreira, espaço físico e estrutural adequado, materiais suficientes e de qualidade para a realização das atividades, recursos financeiros e pedagógicos adequados, tempo para planejar as ações no próprio espaço de trabalho (hora-atividade) pensadas no coletivo, entre outros elementos.

Considerando os aspectos básicos para a formação de professores, Silva (2011) estabelece princípios a serem considerados: a categoria trabalho, a relação teoria e prática, a pesquisa na ação da formação e o papel do professor. Para a autora, o trabalho do professor deve ser analisado em uma perspectiva intelectual, indissociável da teoria e da prática, sendo orientado por objetivos, bem como valorizar o processo histórico em que se constitui a atividade humana, a natureza científica, artística, ética e técnica numa perspectiva crítico-emancipatória.

Tendo em vista esses aspectos, pensar a formação continuada de professores para além de suas experiências profissionais e saberes da prática implica resgatar uma formação baseada numa sólida fundamentação teórica que considere os aspectos sociais e políticos do trabalho docente.

Considerando a formação continuada como um alicerce ao trabalho do professor, valorizando suas experiências e aprendizagens ao longo da trajetória profissional, apresentamos neste artigo as características da proposta do MNPEF enquanto mestrado nacional profissional para o ensino de Física no Brasil. Assim, serão mencionados elementos que descrevem esse programa de formação, bem como seus avanços e algumas reflexões sobre o desenvolvimento desta proposta com base em produções científicas desenvolvidas por outros pesquisadores e que contribuem para sua análise e compreensão.

\section{O MNPEF enquanto proposta de formação continuada para professores de física}

O início da pós-graduação no Brasil, na década de 1960, encontrou condições favoráveis a partir de políticas globais que buscavam recursos humanos qualificados para o desenvolvimento econômico. A partir do Parecer no 977/1965 (BRASIL, 1965), os programas de pós-graduação recém-criados passaram a sofrer forte influência e orientações do padrão norte-americano, criando uma relativa dependência cultural do Brasil com este país. Historicamente, esse processo 
representou um avanço no desenvolvimento da pesquisa, mas, ao mesmo tempo, fortaleceu os mecanismos de controle dos estudos desenvolvidos pelos pesquisadores (SANTOS, 2003).

A pós-graduação stricto sensu em nível de mestrado divide-se em Acadêmico e Profissional. O Mestrado Acadêmico, regulamentado pelo Parecer Sucupira (Parecer CFE no 977/1965) aprovado em 3 de dezembro de 1965 ainda sob vigência da Lei n 4.024, de 1961, detém características de natureza acadêmica e de pesquisa. De acordo com o Parecer, "o mestrado tanto pode ser de pesquisa como profissional", devendo ter como característica grande flexibilidade de modo a oferecer ampla liberdade ao candidato que terá orientação de um diretor de estudos (BRASIL, 2005, p. 166).

Já o Mestrado Profissional, regulamentado pela Portaria MEC n 389, de 23 de março de 2017 e pela Portaria CAPES no 131, de 28 de junho de 2017, visa atender aos profissionais nas diversas áreas do conhecimento, oportunizando o estudo de técnicas que venham a atender à demanda de mercado do setor produtivo (BRASIL, 2014). Este objetivo vai ao encontro da perspectiva neoliberal de educação e de formação já discutidas, voltada às necessidades imediatas da sociedade capitalista. Este fato implica, sem dúvidas, na necessidade de estudos analíticos acerca deste e de outros programas de mestrado profissional, a fim de que seja possível identificar suas limitações, bem como suas potencialidades e caminhos para o desenvolvimento de uma formação crítica e voltada às necessidades da prática social, ainda que dentro do modelo social vigente.

Para manter seu controle e facilitar o processo avaliativo dos programas de mestrado e doutorado, a CAPES organizou o Sistema Nacional de Pós-Graduação (SNPG), estabelecendo 48 (quarenta e oito) áreas do conhecimento, sendo a Área 46 de Ciências e Matemática. Com a reformulação ocorrida pela Portaria CAPES nº 83/2011, esta área passou a ser denominada de “Ensino” (SILVA; DEL PINO, 2016).

Em 2013, foi instituído pela Portaria no 942 da CAPES o Mestrado Nacional Profissional em Ensino de Física, também integrado à área 46 do SNPG, tendo em vista contribuir com a formação continuada de professores de Física em âmbito nacional. O MNPEF pode ser considerado um mestrado em fase inicial de trabalhos, mas que já vem apresentando material científico de produção dos professores participantes, sendo também foco de algumas pesquisas científicas.

Como toda proposta de inovação, o MNPEF parte de princípios que apontam a necessidade de se efetivarem mudanças no contexto atual do ensino de Física no Brasil, buscando superar uma série de problemas vinculados à disciplina, ao número de profissionais que atuam e à formação e à qualificação do trabalho realizado em sala de aula nesta área do conhecimento. Alguns 
estudos indicam essas dificuldades (GASPAR, 1997; COSTA; BARROS, 2015; MOREIRA, 2018; SCHWERZ et al., 2020), apresentando, entre outros aspectos, as condições físicas e materiais inadequadas de trabalho, a quantidade insuficiente de profissionais para suprir a demanda social, os currículos desatualizados, a baixa desvalorização social e salarial docente e a baixa procura por essa área do conhecimento nos cursos de licenciatura.

Entre os estudos realizados especificamente sobre o MNPEF, podemos destacar aqueles desenvolvidos por pesquisadores como Schäfer (2013); Souza (2015); Nascimento (2016); Diestel (2017); Antunes Júnior (2018); Andrade, Silva e Brinatti (2018) e Rebeque, Ostermann e Viseu (2018), os quais, a partir de diferentes perspectivas, demonstram o modelo de formação do curso, as experiências pedagógicas com o uso de diferentes estratégias, os saberes disciplinares desenvolvidos no processo formativo e a análise dos produtos educacionais elaborados pelos professores participantes, tendo em vista melhor compreender esse mestrado enquanto instrumento de formação continuada para profissionais em exercício na disciplina de Física.

O MNPEF recebeu autorização para funcionamento em 2013 com seu reconhecimento pela Portaria n ${ }^{\circ} 942$ da CAPES. Trata-se de um mestrado em nível nacional de pós-graduação na modalidade profissional de iniciativa da SBF e organizado em polos regionais vinculados às Instituições de Ensino Superior (IES). O mestrado é direcionado a professores em exercício nos ensinos Fundamental e Médio que atuam na disciplina de Física e/ou áreas afins, tendo como objetivo principal formar professores no domínio de conteúdos de Física e de teorias e metodologias de ensino que possam ser desenvolvidas no espaço escolar.

Desde a criação o MNPEF vem, por meio de editais específicos, credenciando polos em todo o país, sendo regulamentados pela Sociedade Brasileira de Física (SBF). Cada polo tem editais próprios em conformidade com o Edital Nacional, regido pela Regimento (SBF, 2015 / SBF, 2020) e a Matriz Curricular Nacional (SBF, 2014) (REBEQUE; OSTERMANN; VISEU, 2020).

O site específico do programa apresenta o credenciamento de 63 instituições de Ensino Superior, distribuídos em todas as regiões brasileiras, como mostra a tabela:

Tabela 1 - Distribuição do MNPEF nas regiões brasileiras

\begin{tabular}{|c|c|c|c|c|}
\hline Região & Ano 2013 & Ano 2014 & Ano 2015 & $\begin{array}{c}\text { Total por } \\
\text { região }\end{array}$ \\
\hline Norte & 02 & 04 & 03 & 09 \\
\hline Nordeste & 05 & 06 & 09 & 20 \\
\hline Centro-Oeste & 03 & 02 & 00 & 05 \\
\hline Sudeste & 06 & 08 & 00 & 14 \\
\hline Sul & 02 & 04 & 04 & 10 \\
\hline Total & 18 & 24 & 16 & 58 \\
\hline
\end{tabular}

Fonte: Os autores (2021). 
Totalizam-se 58 polos distribuídos em todo o território brasileiro, sendo a maior concentração na região Nordeste e Sudeste. Os polos 7, 18, 53, 54 e 57 não se apresentam mais como instituições que deram continuidade ao MNPEF, como consta no próprio site do programa. Não se pode afirmar que foram descredenciadas pois tais informações não constam na página da SBF, porém estes não são mais nominados.

Nessa perspectiva, afirmam Rebeque, Ostermann e Viseu (2020, p. 6):

\begin{abstract}
Podemos dizer que o Mestrado Nacional Profissional em Ensino de Física tem cumprido com o seu papel de oferecer cursos de formação continuada para professores de Física atuantes na Educação Básica. Entretanto, acreditamos ser oportuna a reflexão sobre a padronização dos cursos vinculados ao programa, isto é, de polos regionais espalhados por todo território nacional estarem atrelados às práticas acadêmicas pré-determinadas: currículo nacional e trabalho de conclusão.
\end{abstract}

Como mestrado de iniciativa da Sociedade Brasileira de Física (SBF) e enquanto proposta nacional, o MNPEF está presente em todas as regiões do país, atingindo inúmeros profissionais, porém, não apresenta uma preocupação singular em atender aos aspectos da realidade local em que está inserido, sendo este um de seus desafios.

Trata-se de considerar os elementos relevantes de uma proposta de formação pautada nos problemas da realidade dos sujeitos, os aspectos sociais, econômicos e culturais dos professores que poderão realizar o processo seletivo para o ingresso ao mestrado, pois cada profissional traz concepções e experiências de sua realidade e os objetivos do programa devem atender às expectativas daqueles que buscam continuidade em sua formação.

Para Contreras (2012), todo processo formativo tem uma ideologia que pode estar encoberto aos olhos do professor ao ser atribuído certa sofisticação técnica e pelo fato de aparentar uma maior condição de qualificação profissional, uma estratégia que induz à perda da autonomia profissional. É preciso ter clareza que a "administração" de um programa define toda sua estrutura curricular, organizando e indicando os limites de atuação do programa, mantendo o controle de resultados e limitando ações.

O ingresso no MNPEF é realizado a partir das orientações do Edital Regional a partir das vagas específicas para cada polo, sempre respeitando o Edital Nacional. O professor é admitido no mestrado mediante a aprovação na prova escrita nacional e na prova de defesa de memorial, dada a classificação de acordo com o número de vagas definido em casa polo. De acordo com informações dos editais da SBF entre os anos de 2013 e $2020^{1}$, foram ofertadas 4.878 vagas

\footnotetext{
${ }^{1}$ Disponível em: www1.fisica.org.br/mnpef/
} 
distribuídas por todo o território brasileiro, o que demonstra a amplitude e abrangência do programa.

O MNPEF em sua organização curricular abarca três linhas de pesquisa: 1) Física no Ensino Fundamental; 2) Física no Ensino Médio; e 3) Processos de Ensino e Aprendizagem e Tecnologias de Informação e Comunicação no Ensino de Física (PEA). Estas linhas definem as disciplinas obrigatórias e optativas a serem desenvolvidas no programa, com carga horária e créditos estabelecidos. O mestrado apresenta em sua estrutura curricular atual a obrigatoriedade da realização de 32 créditos, sendo 24 definidos pela comissão de pós-graduação nacional, 2 em atividade didática supervisionada e 8 em disciplinas optativas (SBF, 2020). O Quadro 1 apresenta a matriz curricular do programa:

Quadro 1 - Matriz curricular com disciplinas obrigatórias e optativas do MNPEF

\begin{tabular}{|c|c|c|}
\hline \multirow{8}{*}{ 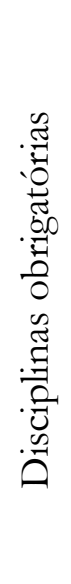 } & Disciplinas & Carga horária/ Créditos \\
\hline & Eletromagnetismo & 60 horas -4 créditos \\
\hline & Mecânica Quântica & 60 horas -4 créditos \\
\hline & Marcos no Desenvolvimento da Física & 30 horas -2 créditos \\
\hline & $\begin{array}{c}\text { Física Contemporânea: Astronomia e } \\
\text { Astrofísica }\end{array}$ & 60 horas -4 créditos \\
\hline & Termodinâmica e Mecânica Estatística & 60 horas -4 créditos \\
\hline & $\begin{array}{c}\text { Fundamentos Teóricos em Ensino e } \\
\text { Aprendizagem }\end{array}$ & 60 horas -4 créditos \\
\hline & Estágio Supervisionado & 30 horas -2 créditos \\
\hline \multirow{4}{*}{ 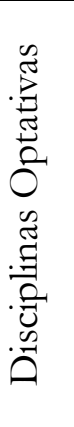 } & $\begin{array}{c}\text { Atividades Experimentais para o Ensino } \\
\text { Médio e Fundamental }\end{array}$ & 60 horas -4 créditos \\
\hline & $\begin{array}{c}\text { Atividades Computacionais para o Ensino } \\
\text { Médio e Fundamental }\end{array}$ & 60 horas - 4 créditos \\
\hline & $\begin{array}{c}\text { Processos e Sequência de Ensino e } \\
\text { Aprendizagem em Física no Ensino Médio e } \\
\text { Fundamental }\end{array}$ & 60 horas -4 créditos \\
\hline & $\begin{array}{c}\text { Física no Ensino Fundamental em uma } \\
\text { Perspectiva Multidisciplinar }\end{array}$ & 60 horas -4 créditos \\
\hline
\end{tabular}

Fonte: Adaptado do regimento do MNPEF (2020).

A matriz curricular estabelecida em um mestrado representa uma forma sistematizada de definir as concepções filosóficas orientadoras da prática pedagógica que norteará o trabalho dos educadores e contribuirá na escolha de metodologias e conteúdos a serem desenvolvidos (SACRISTÁN, 2000). Ao analisar este programa, Rebeque, Ostermann e Viseu (2020), afirmam que a matriz curricular ofertada no MNPEF, ao abranger 50\% de disciplinas específicas de Física, 
busca preencher lacunas da formação inicial baseado em uma concepção de treinamento, sendo construído a partir de interesses e necessidades de determinados grupos sociais.

Convém destacar que as disciplinas optativas ofertadas pelo MNPEF permitem discutir temas atuais para o ensino, agregando metodologias que são importantes para o trabalho educacional, aproximando-se da realidade dos educandos e permitindo novas abordagens pedagógicas. É relevante considerar, porém, que as questões curriculares são abrangentes, envolvendo não apenas conteúdos, mas todo o aporte físico, estrutural, financeiro e técnico que possam subsidiar o trabalho do professor e garantir que sua ação seja autônoma, dependendo das concepções científicas e políticas de cada profissional.

Destaca-se que, apesar das expectativas geradas pelo mestrado, o estudo realizado por Schäfer e Ostermann (2013) discute a problemática dos conteúdos abordados a partir da dicotomia entre os saberes da experiência e os saberes acadêmicos, principalmente ao considerar que, mesmo oferecendo subsídios teóricos, epistemológicos e metodológicos para que os professores alterem sua prática pedagógica a partir dos conhecimentos adquiridos no programa, essa mudança depende do perfil do professor e de suas condições de trabalho.

Concordamos com Villani (2016), quando destaca que a organização de uma proposta curricular traz elementos de interesse de um determinado grupo, resultante de lutas públicas. O MNPEF atende aos anseios dos pesquisadores de Ciências e Matemática, principalmente na área de Física e de Ensino de Física, os quais buscavam desenvolver estratégias e procedimentos de acordo com os conteúdos a serem abordados, buscando articular os saberes científicos, educacionais e a prática pedagógica. Entretanto, segundo o autor, o programa apresenta uma estrutura curricular que enfatiza as disciplinas de conteúdos específicos da Física, o que facilita a ação dos docentes do mestrado, uma vez que a maioria deles já tem ligação com esses conteúdos em suas disciplinas em cursos de graduação.

Para Carvalho e Pérez (1993), é necessário estabelecer a importância dos conteúdos disciplinares na formação dos professores, uma vez que eles constituem uma das bases de conhecimento para a docência. Destacam ainda que o professor precisa adquirir conhecimentos teóricos sobre a aprendizagem das ciências para propor estratégias para o ensino, associando os saberes científicos e a prática pedagógica.

Considerando os aspectos que caracterizam uma proposta curricular, Lopes e Macedo (2011, p. 41) afirmam que: 
[...] o currículo é, ele mesmo, uma prática discursiva. Isso significa que ele é uma prática de poder, mas também uma prática de significação, de atribuição de sentidos. Ele constrói a realidade, nos governa, constrange nosso comportamento, projeta nossa identidade, tudo isso produzindo sentidos. Trata-se, portanto, de um discurso produzido na interseção entre diferentes discursos sociais e culturais que, ao mesmo tempo, reitera sentidos postos por tais discursos e os recria.

Entendemos que o currículo pode contribuir para que o professor compreenda o significado do trabalho que realiza, permitindo-lhe uma postura coerente com as concepções e referenciais pedagógicos que se apropria ao longo do processo formativo em que participa. É preciso ousar e acreditar que, apesar das limitações impostas, é possível que os mestrados e, neste caso particular, o MNPEF, articulem encaminhamentos que possam ampliar a formação dos professores em formação e também a de seus formadores.

O trabalho intitulado "A experiência das disciplinas de formação docente em ensino de Física no MNPEF- UEPG: proposta pedagógica, reflexões e ações” relata uma experiência desenvolvida por um trio de professores do polo 35 do MNPEF que perceberam a possibilidade de articulação e integração entre si, em uma experiência pedagógica curricular, partindo de estudos documentais sobre os aspectos legais, pedagógicos e experienciais em diferentes disciplinas, culminando para a aprendizagem dos conhecimentos científicos que permitem a compreensão das teorias e metodologias para o ensino de Física (ANDRADE; SILVA; BRINATTI, 2018).

O MNPEF é relativamente novo e nessa trajetória são realizadas experiências como aquela apresentada pelos professores do polo 35 , buscando inovações e encaminhamentos adequados que contribuam para o processo formativo de todos os envolvidos. Como afirma Villani (2016, p. 14):

O ponto fundamental seria perceber em que medida nos polos menos organizados os
professores de fato realizaram uma experiência singular, capaz de alavancar novas
iniciativas [.... Por outro lado, também seria preciso verificar em que medida para os
polos mais organizados os recursos de bolsas, a troca com outras instituições e a
possibilidade de outras experiências aumentariam as perspectivas dos professores.

Esses aspectos curriculares de apropriação dos conhecimentos científicos e pedagógicos influenciam diretamente na produção exigida pelo MNPEF. Para a obtenção do título de Mestre em Ensino de Física, o professor deve apresentar publicamente sua dissertação que deverá ser aprovada por banca examinadora. Dessa dissertação deve derivar um produto educacional, considerado pela CAPES (BRASIL, 2019), como uma produção científica que aborda temas de ensino de Física estabelecidos nos currículos do ensino médio ou fundamental, com atividades compreensíveis e reproduzíveis a partir da leitura, devendo ser aplicado em uma ou mais turmas do ensino regular. 
Para Gonçalves et al. (2019), a elaboração e desenvolvimento do produto revela inúmeros desafios, seja na linguagem, na capacidade de ser reaplicado por outras pessoas ou no livre acesso. Entretanto, superados esses e outros desafios, os produtos educacionais precisam apresentar condições reais de ensino para serem desenvolvidos no espaço escolar por outros sujeitos. Como apresentam Moreira e Nardi (2009, p. 4):

\begin{abstract}
O mestrando deve desenvolver, por exemplo, alguma estratégia de ensino, uma nova metodologia de ensino para determinados conteúdos, um aplicativo, um ambiente virtual, um texto; enfim, um processo ou produto de natureza educacional e implementá-lo em condições reais de sala de aula ou de espaços não formais ou informais de ensino, relatando resultados dessa experiência.
\end{abstract}

Desta maneira, o produto educacional se constitui como um material produzido, aplicado e avaliado num determinado contexto educativo e que pode ser utilizado por outros professores, dadas as adequações que se fizerem necessárias. A produção científica contida no produto deve trazer referenciais teóricos que norteiem a maneira de pensar do professor, os conceitos epistemológicos da ciência resultante de seus estudos, as práticas educacionais e os processos formativos vivenciados.

Souza, Rezende e Ostermann (2016) indicam a necessidade de se renovarem questões didáticas e metodológicas na prática docente a partir da elaboração dos produtos educacionais. A maior dificuldade aludida na pesquisa se refere ao rompimento com a tendência do modelo tecnicista, principalmente apontado no currículo e na matriz curricular que constitui a proposta:

\footnotetext{
O conjunto das disciplinas é condizente com o modelo de professor racionalista técnico à medida que o currículo contempla componentes da disciplina básica, de ciência aplicada e de habilidade e atitude; esses últimos ficam nas disciplinas opcionais, enquanto os outros aparecem tanto nas disciplinas obrigatórias quanto nas opcionais (SOUZA; REZENDE; OSTERMANN, 2016, p. 185).
}

De acordo com os autores, há uma preocupação por parte do mestrado em direcionar o produto educacional como mera aplicação de técnicas estudadas nas disciplinas ao longo do programa e desenvolvidas nas salas de aula. Entretanto, para além desta visão racionalista, é possível identificar no MNEPEF a possibilidade de articulação entre a teoria e a prática, contribuindo, por meio de suas disciplinas, para que o professor possa ter o conhecimento científico da Física e também os fundamentos das teorias e técnicas que possam ser utilizadas no desenvolvimento da prática pedagógica em Física. Certamente, essa possibilidade dependerá, em grande medida, da forma como estas disciplinas e produtos educacionais são encaminhados no mestrado. 
Moreira e Nardi (2009), afirmam que o MNPEF tem o potencial de subsidiar a elaboração de estratégias e recursos instrucionais inovadores que podem ser desenvolvidos em sala de aula e, ao mesmo tempo, permitir reflexões quanto ao ensino, a aprendizagem e o conhecimento científico, buscando o equilíbrio e a integração entre as disciplinas que são propostas.

Tais reflexões em relação aos conteúdos científicos e estratégias metodológicas representam um desafio a todos os envolvidos: professores em formação, docentes e ao próprio programa. Trata-se de definir, respectivamente, que profissional almeja ser, que papel desempenha nessa proposta de formação e que objetivos o programa almeja alcançar.

Particularmente, ao professor que participa do mestrado, representa aceitar o confronto com o novo, buscando o aperfeiçoamento dos conteúdos, novas dinâmicas de trabalho e por fim, a inserção na pesquisa científica pode indicar que há algo além do que é comumente desenvolvido na prática pedagógica.

Ao elaborar a dissertação e o produto educacional, o professor retorna à pesquisa, buscando referenciais teóricos que possam subsidiar o trabalho e justificar o percurso metodológico para o alcance dos objetivos almejados. Além disso, a produção destes materiais estimula a interação e troca de experiências entre os professores, permite a divulgação de um material que poderá ser adaptado e utilizado por outros profissionais e oportuniza a participação em eventos de divulgação científica, ampliando as possibilidades de formação docente.

Corroborando com essa discussão, Nesi e Batista (2018), afirmam que o produto educacional elaborado pelos professores se constitui elemento fundamental para analisar aspectos teóricos relativos aos conteúdos específicos da Física e os encaminhamentos didáticos que permitem perceber como essas partes dialogam com a teoria, contribuindo para o processo de ensino-aprendizagem desta Ciência.

Ao analisar o mestrado, Moreira (2018, p. 74) também afirma que a pesquisa aplicada, tal como desenvolvida no MNPEF "pode contribuir muito para melhorar o ensino de Física na medida em que se ocupa de problemas específicos de ensino e envolve professores de Física". A produção realizada pelo professor com auxílio de um orientador permite ao professor um novo caminho para sua formação indicando impasses a serem superados, aprendizagens compartilhadas e a incorporação de novos conhecimentos para a sua prática pedagógica.

Resultante dessa produção, entre os anos de 2013 e 2018, a SBF disponibilizou mais de 300 produtos educacionais provenientes dos polos do MNPEF distribuídos em todo o Brasil. Acessando o material é possível identificar diferentes temáticas do ensino de Física que abrangem temas e conteúdos pouco abordados, tais como Quântica, Relatividade, Física Contemporânea, 
História da Física e Astronomia. Em geral, esses produtos apresentam um olhar diferenciado para o uso de metodologias em sala de aula, com a apresentação de sequências didáticas, jogos, experimentações, redes sociais, tecnologias digitais e outros encaminhamentos e estratégias metodológicas para o trabalho pedagógico na disciplina de Física (ZARA; CASANOVA, 2020).

A produção de um material de autoria própria - neste caso, o produto educacional - deve ter como finalidade possibilitar ao professor relacionar os conhecimentos científicos adquiridos ao longo do mestrado e as práticas pedagógicas vivenciadas no decorrer do seu trabalho. Todavia, isso só é possível se o programa, mesmo diante de suas limitações, oferecer a esses professores em exercício o domínio dos fundamentos científicos, quer relacionados à Física, quer relacionados à Educação e ao Ensino de Física, para a elaboração, o desenvolvimento e a avaliação do produto educacional no âmbito do processo de ensino-aprendizagem. Com o desenvolvimento de um produto educacional, os mestrados profissionais e, neste caso particular, o MNPEF, têm a potencialidade de oferecer aos professores que o cursam não apenas o domínio teórico, mas também o conhecimento prático sobre o modo como o saber se articula na práxis pedagógica, propiciando-lhes, para além da aprendizagem de novas metodologias, estratégias e recursos educacionais, a compreensão e o domínio de seus fundamentos, a fim de que possam, efetivamente, desenvolver um trabalho docente intencional, consciente e de qualidade. Do contrário, este mestrado tenderá a tornar-se mais um dos muitos instrumentos de alienação do trabalho do professor numa perspectiva pragmática de formação voltada apenas às necessidades imediatas e utilitaristas de um trabalho pedagógico esvaziado de conhecimento e de sentido. Vale ressaltar que as dissertações e os produtos educacionais delas resultantes podem ser livremente acessadas nas páginas específicas de cada polo e também no site da SBF por todos aqueles que tenham interesse em conhecer os trabalhos desenvolvidos pelos professores ou mesmo utilizá-los em sua prática pedagógica, dadas as alterações e adaptações necessárias a cada contexto.

\section{Considerações finais}

Este trabalho demonstra possibilidades de reflexão sobre a formação continuada de professores, permitindo-nos entender os mestrados profissionais, em especial o MNPEF, como um caminho de qualificação docente. Não há dúvidas de que as mudanças inseridas na sociedade têm exigido novos desafios para os profissionais da educação e para as instituições credenciadas neste programa. Apesar das limitações, o MNPEF tem se apresentado como uma oportunidade de se repensar, discutir e replanejar o ensino de Física a partir de novos fundamentos e perspectivas. 
Enquanto objeto de estudo, o MNPEF vêm sendo tratado por pesquisadores de diferentes instituições a partir de diferentes focos. Os resultados desses estudos indicam avanços, limitações e propostas reflexivas do mestrado sobre como ampliá-lo e promover melhorias, tornando-o uma possibilidade de formação continuada em que o professor em exercício possa ampliar seus conhecimento e horizontes acadêmicos e repensar suas concepções e metodologias na busca por uma educação de qualidade socialmente referenciada no desenvolvimento do processo de ensinoaprendizagem.

O MNPEF traz a continuidade dos estudos em nível de pós-graduação stricto sensu a partir de disciplinas específicas e voltadas para o ensino, inserção de novas metodologias pedagógicas, trocas de experiências com outros profissionais e retomada dos estudos, contribuindo para uma formação mais qualificada na área. Entendemos que este mestrado - assim como qualquer outro de maneira isolada não soluciona os problemas educacionais, mas pode apresentar-se como uma alternativa para uma formação continuada de qualidade a professores de Física.

O programa está distribuído em todo território nacional, concentrando o maior número de polos nas regiões Nordeste (20) e Sudeste (14) e menor número no Centro-Oeste (5), Norte (9), Sul (10), trazendo menos possibilidades para os profissionais que residem nestes locais.

Além da necessidade de sua ampliação nessas localidades, convém destacar a autonomia que cada polo tem desfrutado diante das decisões que precisam ser realizadas no programa, principalmente ao ser apresentado no regimento (2020) no capítulo IV, das Responsabilidades Compartilhadas, uma série de incumbências ao polo de ações administrativas. Quando o polo requer verbas para a realização de atividades específicas, por exemplo, torna-se necessário enviar solicitação para a Coordenação de Pós-Graduação (CPG), limitando inclusive a organização de eventos para divulgação das atividades de cada polo. Portanto, torna-se necessário maior flexibilização administrativa para as Instituições de Ensino Superior que agregam o programa, a fim de que possam assumir decisões operacionais específicas permitindo maior autonomia para o polo na resolução problemas que lhes são pontuais e específicos daquela realidade.

Além disso, consideramos ser importante que as IES disponham de mais recursos para a proposição e desenvolvimento de novos projetos e programas de formação, o que implica, também, na melhoria de suas estruturas e adequações nas condições de trabalho de seus profissionais em atividades que envolvam ensino, pesquisa e extensão. Outrossim, faz-se necessário um maior reconhecimento social e financeiro e melhores condições de trabalho e de carreira dos docentes da educação básica para que, em exercício, possam investir na continuidade de sua formação, o que inclui os mestrados profissionais. 
Outro aspecto que merece reflexão se refere à forma como é realizado o processo seletivo para o ingresso no MNPEF. Quando se propõe um processo seletivo com fases eliminatórias, restringe-se a oportunidade de mais profissionais participarem do processo. Nesse sentido, é pertinente refletir sobre o objetivo do mestrado em atender aos profissionais em exercício e pensar em uma proposta que não seja eliminatória para o ingresso, permitindo que as vagas sejam preenchidas em sua totalidade e garantindo maior acessibilidade. Além disso, outras limitações relacionadas às condições de trabalho podem dificultar a participação dos professores da educação básica no MNPEF, tais como carga horária elevada de trabalho, necessidade de longos deslocamentos para ter acesso ao polo, pouco tempo disponível para a realização das atividades promovidas pelo programa, além de questões vinculadas à sua profissão que podem resultar na precarização do seu trabalho. Além disso, outros fatores podem influenciar a participação dos professores no programa, tais como as limitações de suas ações pedagógicas e a falta de incentivo financeiro e plano de carreira profissional.

Quanto ao currículo do MNPEF, a disposição das disciplinas converge para uma carga horária superior voltada às disciplinas específicas de Física, podendo as optativas direcionar os estudos para a área de ensino, com foco nas diferentes metodologias que podem ser utilizadas pelo professor. Apesar de poucas, as disciplinas optativas permitem que o professor possa direcionar sua formação considerando suas necessidades, particularidades e interesses.

No que se refere ao produto educacional, as críticas sobre ele desenvolvidas têm enfatizado sua racionalidade prática voltada a problemas pontuais e imediatos do ensino-aprendizagem. Entretanto, a depender da forma como forem trabalhados dentro do programa, esses produtos podem ser entendidos como uma oportunidade de retorno do professor à pesquisa, permitindolhe a articulação entre teoria e prática alicerçada em fundamentos científicos e tecnológicos que possam contribuir não apenas para sua formação, mas, igualmente, para a aprendizagem dos estudantes.

Assim como Paro (2012), entendemos que o problema da educação brasileira não é um problema apenas de estratégias, de técnicas ou de métodos de ensino, mas, acima de tudo, de objetivos. Enquanto a política educacional brasileira, em sua totalidade, não estiver comprometida com a formação de seus educadores e com a democratização do conhecimento científico a todos, indistintamente, nenhuma estratégia ou recurso diferenciado acionado pelo professor em seu processo formativo ou em sua prática dará conta de resolver os entraves existentes no processo de ensino-aprendizagem e de garantir uma educação de qualidade socialmente referenciada. 


\section{Referências}

ANDRADE, André Vitor Chaves de; SILVA, Silvio Luiz Rutz da; BRINATTI, André Maurício. 1A024 Fundamentos teóricos de ensino e aprendizagem: visões necessárias para a construção do saber docente no mestrado nacional profissional em ensino de física - polo 35, UEPG. Tecné, Episteme y Didaxis: TED, 2018.

ANDRÉ, Marli Eliza Dalmazo Afonso de. Formação de professores: a constituição de um campo de estudos. Educação, Porto Alegre, v. 33, n. 3, p. 174-181, set./dez. 2010. Disponível em: http://revistaseletronicas.pucrs.br/ojs/index.php/faced/article/viewFile/8075/5719. Acesso em: 2 jan. 2021.

ANTUNES JÚNIOR, Estevão Luciano Quevedo. Formação continuada de professores em larga escala: um estudo sobre o Mestrado profissional em ensino de física. 2018. 82f. Dissertação (Mestrado em Ensino de Física) - Pós-Graduação em Ensino de Física, Instituto de Física, Universidade Federal do Rio Grande do Sul, Porto Alegre, 2018.

BARROS, Aidil Jesus da Silveira; LEHFELD, Neide Aparecida de Souza. Fundamentos de metodologia científica. 3. ed. São Paulo: Pearson Universidades, 2007.

BRASIL. Fundação Coordenação de Aperfeiçoamento de Pessoal de Nível Superior - CAPES. Portaria no 80, de 16 de dezembro de 1998. Dispõe sobre o reconhecimento dos mestrados profissionais e dá outras providências. Diário Oficial da União, Brasília, DF, 11 jan. 1999.

Disponível em: https://abmes.org.br/legislacoes/detalhe/2183/portaria-capes-n-80. Acesso em: 25. jan. 2021.

BRASIL. Ministério da Educação. Conselho Federal de Educação. Parecer CFE no 977/65 (Parecer Sucupira), aprovado em 3 dez. 1965. Rev. Bras. Educ., n. 30, dez. 2005. DOI: https://doi.org/10.1590/S1413-24782005000300014

BRASIL. Ministério da Educação. Conselho Nacional de Educação. Parecer CNE/CES no 79/2002, de 12 de março de 2002. Interessado: MEC/Universidade Federal de Pernambuco. Consulta sobre titulação de programa mestrado profissionalizante. Diário Oficial da União, Brasília, DF, 11 abr. 2002. Disponível em: http://portal.mec.gov.br/cne/arquivos/pdf/2002/pces079_02.pdf. Acesso em: 25. jan. 2021.

BRASIL. Ministério da Educação. Conselho Nacional de Educação. Resolução CNE/CP n ${ }^{\circ}$ 2, de 20 de dezembro de 2019. Define as Diretrizes Curriculares Nacionais para a Formação Inicial de Professores para a Educação Básica e institui a Base Nacional Comum para a Formação Inicial de Professores da Educação Básica (BNC-Formação). Diário Oficial da União, Brasília, DF, 10 fev. 2020. Disponível em: http://portal.mec.gov.br/docman/dezembro-2019-pdf/135951-rcp00219/ file. Acesso em 10. jan. 2021.

BRASIL. Ministério da Fazenda; Ministério do Planejamento, Orçamento e Gestão; Ministério da Educação. Lei no 13.005, de 25 de junho de 2014. Aprova o Plano Nacional de Educação - PNE e dá outras providências. Diário Oficial da União, Brasília, DF, 26 jun. 2014. 
BRZEZINSKI, Iria. Políticas contemporâneas de formação de professores para os anos iniciais do ensino fundamental. Educ. Soc., Campinas, v. 29, n. 105, p. 1139-1166, set./dez. 2008. DOI: https://doi.org/10.1590/S0101-73302008000400010

CARVALHO, Anna Maria Pessoa de; GIL-PÉREZ, Daniel. Formação de professores de ciências: tendências e inovações. São Paulo: Cortez, 1993.

CONTRERAS, José. A autonomia de professores. São Paulo: Cortez, 2012.

COSTA, Luciano Gonsalves; BARROS, Marcelo Alves. O ensino da Física no Brasil: problemas e desafios. In: ENDUCERE: XII Congresso Nacional de Educação. Anais, 2015.

DIESTEL, André Luiz Cosenza. Uma análise de produtos educacionais para o ensino de física quântica desenvolvidos no âmbito de um Mestrado profissional em ensino de física. 2017. 82f. Dissertação (Mestrado em Ensino em Física) - Pós-Graduação em Física, Instituto de Física, Universidade Federal do Rio Grande do Sul, Porto Alegre, 2017.

DUARTE NETO, José Henrique. A epistemologia da prática: implicações para a formação de professores da educaşão básica. Jundiaí: Paco Editorial, 2013.

FACCI, Marilda Gonçalves Dias. Valorização ou esvą̧iamento do trabalho do professor? um estudo críticocomparativo da teoria do professor reflexivo, do construtivismo e da psicologia vigotskiana. Campinas: Autores Associados, 2004.

FREITAS, Helena Costa Lopes de. Formação de professores no Brasil: 10 anos de embate entre projetos de formação. Educação \& sociedade, Campinas, v. 23, n. 80, p.137-168, set. 2002.

FREITAS, Helena Costa Lopes de. Certificação docente e formação do educador: regulação e desprofissionalização. Educação \& Sociedade, v. 24, p. 1095-1124, 2003.

FREITAS, Helena Costa Lopes de. A (nova) política de formação de professores: a prioridade postergada. Educação \& Sociedade, v. 28, n. 100, p. 1203-1230, 2007.

GASPAR, Alberto. Cinquenta anos de ensino de física: muitos equívocos, alguns acertos e a necessidade do resgate do papel do professor. In: XV Encontro de Físicos do Norte e Nordeste, p. 11, 1997.

GIL, Antonio Carlos. Como elaborar projetos de pesquisa. São Paulo: Atlas, 2002.

GONÇALVES, Carmen Érica Lima de Campos; OLIVEIRA, Carolina de Souza; MAQUINÉ, Gilmara Oliveira; MENDONÇA, Andréa Pereira. (Alguns) desafios para os produtos educacionais nos mestrados profissionais nas áreas de ensino e educação. Revista de Estudos e Pesquisas sobre Ensino Tecnológico - EDUCITEC, v. 5, n. 10, 2019.

LOPES, Alice Casimiro; MACEDO, Elizabeth. Teorias do currículo. São Paulo: Cortez, 2011.

MOREIRA, Marco Antônio. Uma análise crítica no Ensino de Física. Estudos Avançados, v. 32, n. 94, 2018. 
MOREIRA, Marco Antônio.; NARDI, Roberto. O mestrado profissional na área de Ensino de Ciências e Matemática: alguns esclarecimentos. Revista Brasileira de Ensino de Ciência e Tecnologia, v. 2, n. 3, p. 1-9, 2009.

NASCIMENTO, Matheus Monteiro. Análise de produtos educacionais desenvolvidos no âmbito de um mestrado profissional em ensino de física. 2016. 222f. Dissertação (Mestrado em Ensino de Física) Pós-Graduação em Ensino de Física, Instituto de Física, Universidade Federal do Rio Grande do Sul, Porto Alegre, 2016.

NESI, Elisângela Rovaris. PDE: possibilidades e limites da formação teórico-metodológica dos professores de matemática do NRE/FB (2007-2013). 2015. 169 f. Dissertação (Mestrado em Educação) - PósGraduação em Educação, Centros de Ciências Humanas, Universidade Estadual do Oeste do Paraná, Francisco Beltrão, 2015.

NESI, Elisângela Rovaris; BATISTA, Michel Corci. Produtos educacionais elaborados no Mestrado Profissional em Ensino de Física: a busca por referenciais norteadores. Revista Valore, v. 3, p. 554-563, 2018.

PARO, Vitor Henrique. Administração escolar-Introdução crítica. São Paulo: Cortez, 2012.

PIMENTA, Selma Garrido; GHEDIN, Evandro (org.). Professor Reflexivo no Brasil: gênese e crítica de um conceito. 3. ed. São Paulo: Cortez, 2005.

REBEQUE, Paulo Vinícius; OSTERMANN, Fernanda; VISEU, Sofia. O mestrado nacional profissional em ensino de física: investigando os modos de regulação em um polo regional do programa. Revista Brasileira de Pesquisa em Educação em Ciências, v. 18, n. 2, p. 399-428, 2018. DOI: https://doi.org/10.28976/1984-2686rbpec2018182399

REBEQUE, Paulo Vinícius; OSTERMANN, Fernanda; VISEU, Sofia. A nova gestão pública no contexto da formação continuada de professores: o caso do mestrado nacional profissional em ensino de física. Ciência \& Educação, Bauru, v. 26, e20022, p. 1-16, 2020. DOI:

https://doi.org/10.1590/1516-731320200022

ROMANOWSKI, Joana Paulin. Apontamentos em pesquisas sobre formação de professores: contribuições para o debate. Revista Diálogo Educacional, v. 12, n. 37, p. 905-924, 2012.

SACRISTAN, José Gimeno. O currículo: uma reflexão sobre a prática. Porto Alegre: Artmed, 2000.

SANTOS, Cássia Miranda dos. Tradições e contradições da pós-graduação no Brasil. Educação \& Sociedade, Campinas, vol. 24, n. 83, p. 627-641, agosto 2003.

SANTOS, Edlamar Oliveira dos; BATISTA NETO, José. Concepções e práticas de formação continuada na educação básica. Revista Interritórios, Caruaru, v. 2, n. 3, p. 101-120, 2016.

SCHÄFER, Eliane Dias Alvarez. Impacto do mestrado profissional em ensino de física da UFRGS na prática docente: um estudo de caso. 2013. 338f. Tese (Doutorado em Ensino de Física) - PósGraduação de Ensino de Física, Instituto de Física, Universidade Federal do Rio Grande do Sul, Porto Alegre, 2013. 
SCHÄFER, Eliane Dias Alvarez; OSTERMANN, Fernanda. O impacto de um mestrado profissional em ensino de física na prática docente de seus alunos: uma análise bakhtiniana sobre os saberes profissionais. Ensaio Pesquisa em Educação em Ciências, Belo Horizonte, v. 15, n. 2, p. 87103, 2013.

SCHWERZ, Roseli Constantino; DEIMLING, Natalia Neves Macedo; DEIMLING, Cesar Vanderlei; SILVA, Daniele Cristina da. Considerações sobre os indicadores de formação docente no Brasil. Pro-Posições, v. 31. 2020. DOI: https://doi.org/10.1590/1980-6248-2017-0199

SHIROMA, Eneida Oto; MORAES, Maria Célia Marcondes de; EVANGELISTA, Olinda. Politica educacional. Rio de Janeiro: Lamparina, 2011.

SILVA, Kátia Augusta Curado Pinheiro Cordeiro da. A formação de professores na perspectiva crítico-emancipadora. Linhas Críticas, v. 17, n. 32, p. 13-32, 2011. DOI: 10.26512/lc.v17i32.3668. Disponível em: https://periodicos.unb.br/index.php/linhascriticas/article/view/3668. Acesso em: 18 abr. 2021.

SILVA, Priscila Albertasse Dutra; DEL PINO, José Cláudio. O mestrado profissional na área de ensino. Holos, v. 8, p. 318-337, 2016.

SOCIEDADE BRASILEIRA DE FÍSICA. Mestrado Nacional Profissional em Ensino de Física - MNPEF. Regimento geral. 11 mar. 2015. Disponível em:

http://www.sbfisica.org.br/ mnpef/images/Regimento_MNPEF_16_12_2015_.pdf. Acesso em: 28. ago. 2019.

SOUZA, Josiane de. Apropriação discursiva de modelos de formação docente em trabalhos de conclusão de um mestrado profissional em ensino de física. 2015. 113f. Dissertação (Mestrado em Ensino de Física) Pós-Graduação de Ensino de Física, Instituto de Física, Universidade Federal do Rio Grande do Sul, Porto Alegre, 2015.

SOUZA, Josiane de; REZENDE, Flavia; OSTERMANN, Fernanda. Apropriação discursiva de modelos de formação docente em trabalhos de conclusão de um mestrado profissional em ensino de física. Ensaio Pesquisa em Educação em Ciências, Belo Horizonte, v. 18, n. 2, p. 171-199, 2016.

VILLANI, Alberto. Mestrado profissional em ensino de ciência e matemática: uma interpretação. Revista Ibero-americana de estudos em educaşão, v. 11, n. 1, p. 418-433, 2016.

ZARA, Reginaldo Aparecido; CASANOVA, Samuel Squinalli. Análise dos produtos educacionais provenientes do mestrado nacional profissional em ensino de física. Arquivos do Mudi, v. 24, n. 3, p. 267-276, 1 dez. 2020. 